DOI 10.37882/2223-2982.2021.01-2.24

\title{
ОЦЕНКА СОВРЕМЕННЫХ ПОДХОДОВ К ПОДГОТОВКЕ СПОРТСМЕНОВ-ФИГУРИСТОВ НА ОСНОВЕ ИНДИВИДУАЛЬНОГО ПОДХОДА
}

\section{ASSESSMENT OF MODERN APPROACHES TO THE TRAINING \\ OF FIGURE SKATERS ON THE BASIS OF AN INDIVIDUAL APPROACH}

A. Shibnev

Summary: The article is devoted to the experimental substantiation of the effectiveness of an individual approach in the training of figure skaters. It is shown that the implementation of an individual approach in the training process allows you to take into account the individual psychological qualities of athletes and increase the effectiveness of the training and competitive processes. The results of the study of the dynamics of sports-important qualities of figure skaters during the implementation of the program of individual psychological support are presented. The program used variable personality-oriented techniques and methods for developing achievement motivation, leadership and strong-willed qualities of athletes; technology of cooperation in the "coach - athlete - activity» system; monitoring the effectiveness of training and competitive activities of figure skaters. The results of the study showed a positive dynamics of the development of sportsimportant qualities in the experimental group of skaters after the implementation of the program.

Keywords: figure skaters, individual approach, personality-oriented approach, sports-important qualities, individual support program.
$\mathrm{H}$ а современном этапе развития теории и практики спортивной подготовки спортсменов-фигуристов актуальным становится организация учебно-тренировочного процесса на основе индивидуального подхода. Индивидуальный подход представляет собой комплексную работу, включающую технико-тактическую, физическую, психологическую подготовку на основе избирательной направленности развития физических и волевых качеств спортсменов, управление величиной нагрузок с использованием средств контроля за состоянием спортсменов-фигуристов.

В достижении высоких спортивных результатов в учебно-тренировочной и соревновательной деятельности большую роль играют спортивно-важные качества спортсменов-фигуристов, в основе которых лежит мотивация достижения в спортивной деятельности, связанная с личностными и волевыми качествами личности спортсмена $[1 ; 4]$. Реализация индивидуального подхода

\author{
Шибнев Антон Владимирович \\ Аспирант, Московский государственный \\ педагогический университет \\ Antonshibnev@yandex.ru
}

Аннотация: Статья посвящена экспериментальному обоснованию эффективности индивидуального подхода в процессе подготовки спортсменов-фигуристов. Показано, что реализация индивидуального подхода в учебно-тренировочном процессе позволяет учитывать индивидуально-психологические качества спортсменов и повысить результативность учебно-тренировочного и соревновательного процессов. Представлены результаты исследования динамики спортивно-важных качеств спортсменов-фигуристов в ходе реализации программы индивидуального психологического сопровождения. В программе были использованы вариативные личностно-ориентированные приемы и методы развития мотивации достижения, лидерских и волевых качеств спортсменов; технология сотрудничества в системе «тренер - спортсмен - деятельность»; мониторинг результативности учебно-тренировочной и соревновательной деятельности спортсменов-фигуристов. Результаты исследования показали положительную динамику развития спортивно-важных качеств в экспериментальной группе фигуристов после реализации программы.

Ключевые слова: спортсмены-фигуристы, индивидуальный подход, личностно-ориентированный подход, спортивно-важные качества, программа индивидуального сопровождения.

позволяет учитывать индивидуально-психологические качества спортсменов и повысить результативность учебно-тренировочного и соревновательного процессов.

С целью оценки эффективности организации учебно-тренировочного процесса на основе индивидуального подхода было проведено исследование динамики спортивно-важных качеств спортсменов-фигуристов в ходе реализации программы индивидуального психологического сопровождения учебно-тренировочного процесса. В качестве методов исследования применялись методика исследования волевой организации личности, которая включает следующие шкалы: ценностно-смысловая организация личности (Ц), организация деятельности (О), решительность (Р), настойчивость (Н), самообладание (C), самостоятельность (СМ), общий показатель, характеризующий волевую организацию личности (В).

В ходе исследования были сформированы 2 группы 
спортсменов-фигуристов, всего 30 человек. Экспериментальную группу (ЭГ) составили спортсмены-фигуристы в количестве 15 человек, которые были включены в программу индивидуального психологического сопровождения учебно-тренировочного процесса. В данной программе были реализованы следующие условия: использование вариативных личностно-ориентированных приемов и методов развития целеполагания, мотивации достижения, лидерских и волевых качеств спортсменов в учебно-тренировочном процессе; реализация технологии сотрудничества и продуктивного взаимодействия в системе «тренер - спортсмен - деятельность»; внедрение мониторинга результативности учебно-тренировочной и соревновательной деятельности и волевых качеств спортсменов-фигуристов. Контрольную группу (КГ) составили спортсмены-фигуристы в количестве 15 человек, которые не были включены в данную программу.

В основу программы индивидуального психологического сопровождения учебно-тренировочного процесса были положены идеи, принципы, методы и технологии личностно-ориентированного обучения в организации учебно-тренировочного процесса, который позволяет реализовывать индивидуальный подход к каждому спортсмену. Индивидуальный подход включает ряд идей и принципов. Во-первых, необходимым является воплощение идеи единого мотивационно-ценностного пространства спортивной деятельности - сообщества спортсменов и тренера, объединенных общими ценностями и целями саморазвития в учебно-тренировочной и соревновательной деятельности. Мотивационно-ценностное пространство спортивной деятельности объединяет несколько разнородных сред:

- учебно-тренировочную среду, в которой происходит непосредственное обучение фигуристов;

- соревновательную среду, в которой, с одной стороны, проявляются результаты учебно-тренировочного процесса, с другой - осуществляется соревновательный процесс;

- социальную среду, в которой результаты спортивной деятельности проявляются в формировании новых ценностей, мотивов и направлений развития личности спортсмена-фигуриста.

Организация ценностно-мотивационного пространства возможна при условии учета индивидуально-психологических качеств фигуриста как личности, обладающей своей неповторимостью, способностей, интересов и мотивов [4].

Во-вторых, продуктивным являются идея личностноориентированного подхода. Личностно-ориентированный подход меняет парадигму системы обучения спортсменов-фигуристов, в которой спортсмен становится личностью, «сознательно выбирающий индивидуальную образовательную траекторию в соответствии со своими интересами и способностями» [2, с. 269]. Индивидуальность спортсмена-фигуриста, помимо особенностей функционального развития, физической, технико-тактической, интеллектуальной, волевой подготовленности, также проявляется в том, что он имеет: жизненный опыт практической деятельности, ее оценки и самооценки, наполненный позитивными и негативными переживаниями; личную программу развития; эмоциональную картину внутреннего и внешнего мира; личные интересы, которые выражаются в системе приоритетов определенных видов деятельности; иерархию потребностей, мотивов, ценностей, установок и убеждений. Учебнотренировочный процесс с позиций личностно-ориентированного подхода предполагает:

- целостный взгляд на спортсмена как на личность, для которой спортивная деятельность - это средство решения возникающий жизненных задач, внутренних проблем;

- ориентацию на потребности, личный опыт и уровень актуального развития личности спортсмена и построение учебно-тренировочного процесса в зоне его ближайшего развития;

- субъект-субъектный тип взаимодействия между тренером и спортсменом, имеющим собственные мотивы, цели деятельности и способности для ее осуществления;

- базовой становится продуктивная, творческая деятельность, а репродуктивная, направленная на отработку системы отдельных умений и навыков, выступает в роли вспомогательной по отношению к базовой;

- учебно-тренировочный процесс представляет собой некоторый цикл: от проблемной ситуации к деятельности спортсмена по анализу ситуации и постановке проблемы, а далее к рефлексии способа решения и самоизменений, многократное прохождение которого обеспечивает развитие способностей, рост его самостоятельности и субъективности.

Индивидуальный подход меняет и характер взаимодействия тренер - спортсмен, в котором осуществляется переход от доминанты воспитательного воздействия к доминанте воспитательного взаимодействия. Это означает активное двустороннее движение к общей цели на основе «субъект - субъектного» равенства тренера и его воспитанника. Важнейшей характеристикой субъект - субъектного взаимодействия является диалог. Диалог субъектов учебно-тренировочного процесса рождает их сотрудничество. Реализация принципа сотрудничества предусматривает изменение характера участия тренера в совместной деятельности со спортсменами в зависимости от уровня их развития, которое происходит на основе:

- получения адекватного представления тренера о спортсменах и спортсменов о тренере с помощью 
психологического и социально-психологического тестирования, что ведёт к достижению взаимопонимания, осознанию единства целей;

- установления личностных, эмоционально-положительных отношений в системе «тренер - спортсмен» и «спортсмен - спортсмен»;

- предоставления самостоятельности спортсменам в постановке и решении целей и задач при равноправном участии тренера;

- выработки форм индивидуальной и коллективной ответственности;

- разработки технологий реализации совместно принятых решений и форм взаимной помощи в разнообразной значимой для спортсменов деятельности;

- развития воспитательных ситуаций в направлении актуализации и удовлетворения всё более глубинных и сущностных потребностей и мотивов спортсменов-фигуристов [3].
В программе индивидуального психологического сопровождения спортсменов-фигуристов психологическими механизмами реализации индивидуального подхода выступали рефлексия ограничений в спортивной деятельности; актуализация целей и ценностей спортивной деятельности; развитие навыков целеполагания в учебно-тренировочном и соревновательном процессах.

В ходе предварительной диагностики до реализации программы индивидуального психологического сопровождения спортсменов-фигуристов, был определен начальный уровень спортивно-важных качеств фигуристов ЭГ и КГ. Оценка эквивалентности экспериментальной и контрольной групп спортсменов подтверждена данными статистического анализа с помощью W- критерия Вилкоксона, в ходе которого статистически значимых различий между показателями спортивноважных качеств в исследуемых группах спортсменов не обнаружено. После реализации программы индивидуального психологического сопровождения спортсме-

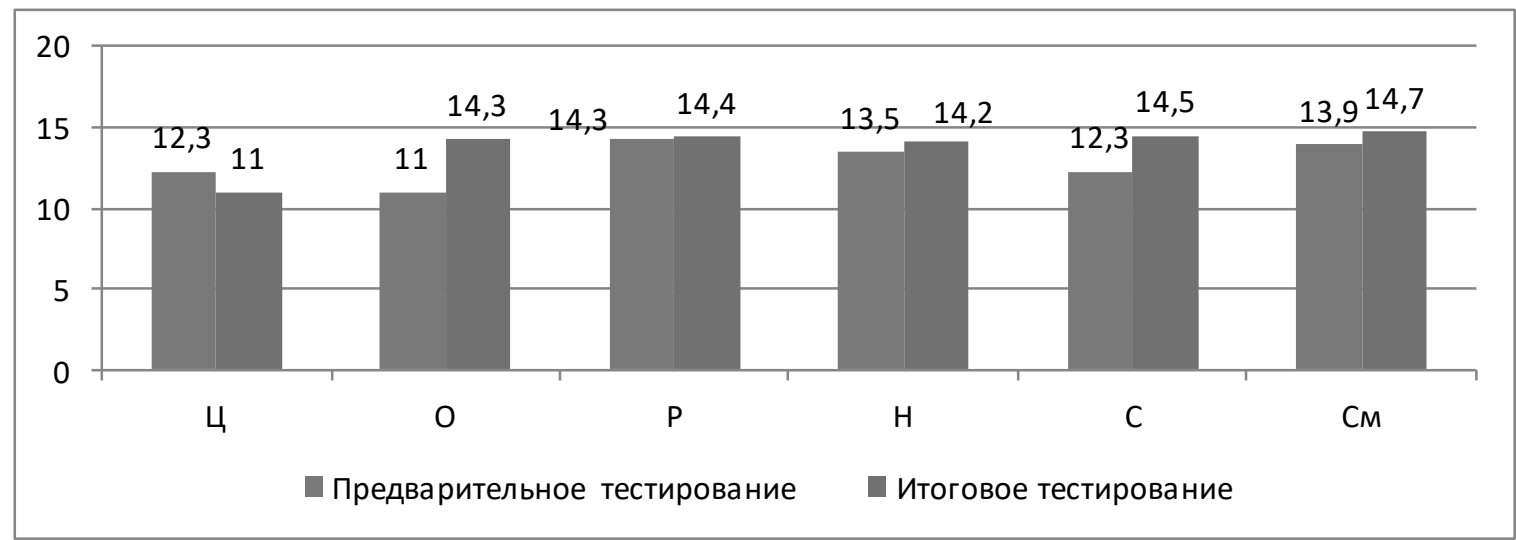

Показатели : Ц - ценностно-смысловая организация личности, О - организация деятельности, Р -. решительность, Н - настойчивость, С- самообладание, См- самостоятельность.

Рис. 1. Динамика спортивно-важных качеств личности спортсменов-фигуристов ЭГ

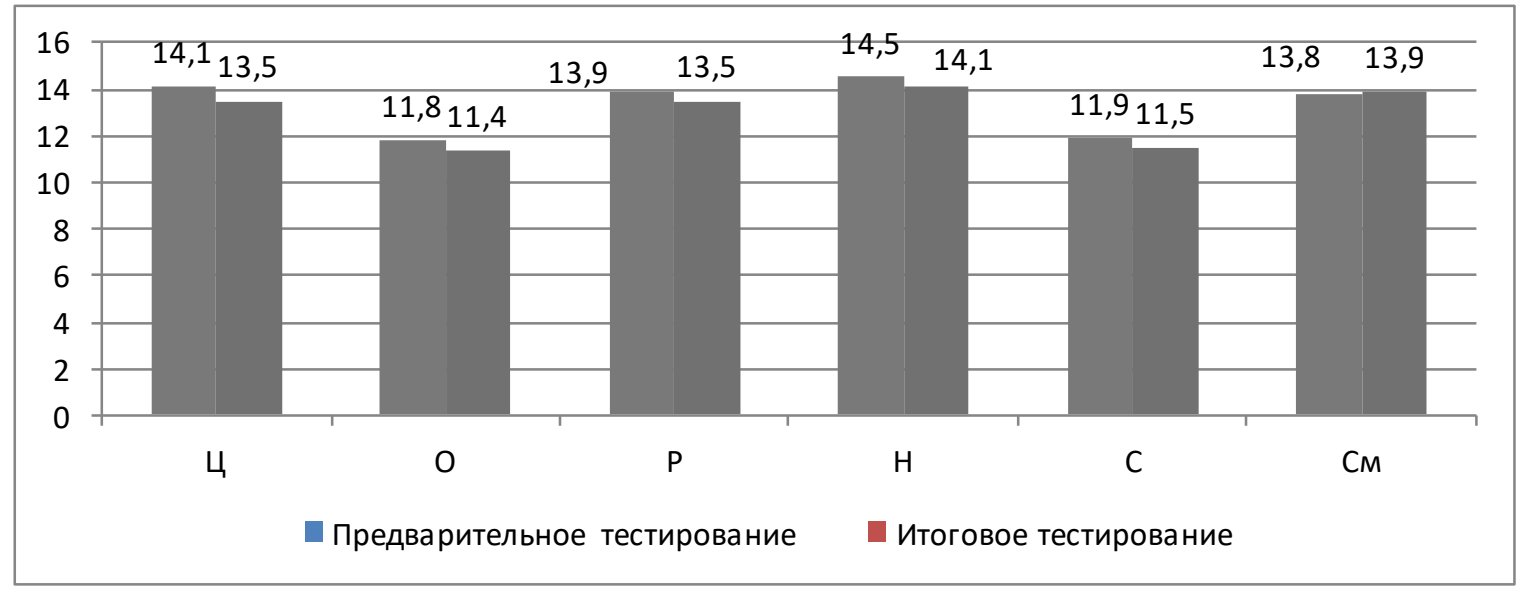

Показатели: Ц - ценностно-смысловая организация личности, О - организация деятельности, Р -. решительность, Н - настойчивость, С- самообладание, См - самостоятельность.

Рис. 2. Динамика спортивно-важных качеств личности спортсменов-фигуристов КГ 
нов-фигуристов был определен итоговый уровень спортивно-важных качеств спортсменов-фигуристов ЭГ и КГ.

Динамика спортивно-важных качеств спортсменовфигуристов ЭГ представлена на рисунке 1.

В ходе реализации программы индивидуального психологического сопровождения в экспериментальной группе спортсменов выявлена статистически значимая положительная динамика качеств, связанных с организацией деятельности $(\mathrm{W}=110,5)$ и самообладанием $(\mathrm{W}=80,5)$.

В контрольной группе теннисистов, напротив, в ходе предварительного и итогового тестирования выявлено статистически значимое снижение по показателям цен- ностно-смысловой организации личности $(\mathrm{W}=0)$, настойчивости $(\mathrm{W}=24,5)$, самообладания $(\mathrm{W}=0)$, что обусловлено влиянием тренировочного процесса (Рис. 2).

Таким образом, при сопоставлении результатов предварительного и итогового тестирования достоверная положительная динамика в развитии спортивно-важных качеств личности, а именно организации спортивной деятельности и самообладания выявлена только в экспериментальной группе фигуристов. Полученные результаты подтвердили результативность программы индивидуального психологического сопровождения спортсменовфигуристов на основе реализации индивидуального подхода в учебно-тренировочной деятельности.

\section{ЛИТЕРАТУРА}

1. Бойко И.И. Мотивация достижения у подростков-спортсменов и ее развитие в процессе проведения коррекционно-тренинговых занятий: дис. ... канд. психологических наук. - Иркутск, 2006. - 161 с.

2. Гершунский Б.С. Философия образования. - М.: Флинта, 1998. - 432 с.

3. иселёва Е.В. Формирование субъект-субъектных отношений в воспитании спортсменов // Теория и практика физической культуры. - № 9. - 2004. - С.59-63.

4. Кузьмин Е.Б. Формирование спортивной мотивации как психолого-педагогическая проблема / Е.Б. Кузьмин, Ю.П. Денисенко, Г.Л. Драндров // Физическая культура: воспитание, образование, тренировка. - 2010. - № 1. - С. 57-61.

() Шибнев Антон Владимирович (Antonshibnev@yandex.ru).

Журнал «Современная наука: актуальные проблемы теории и практики»

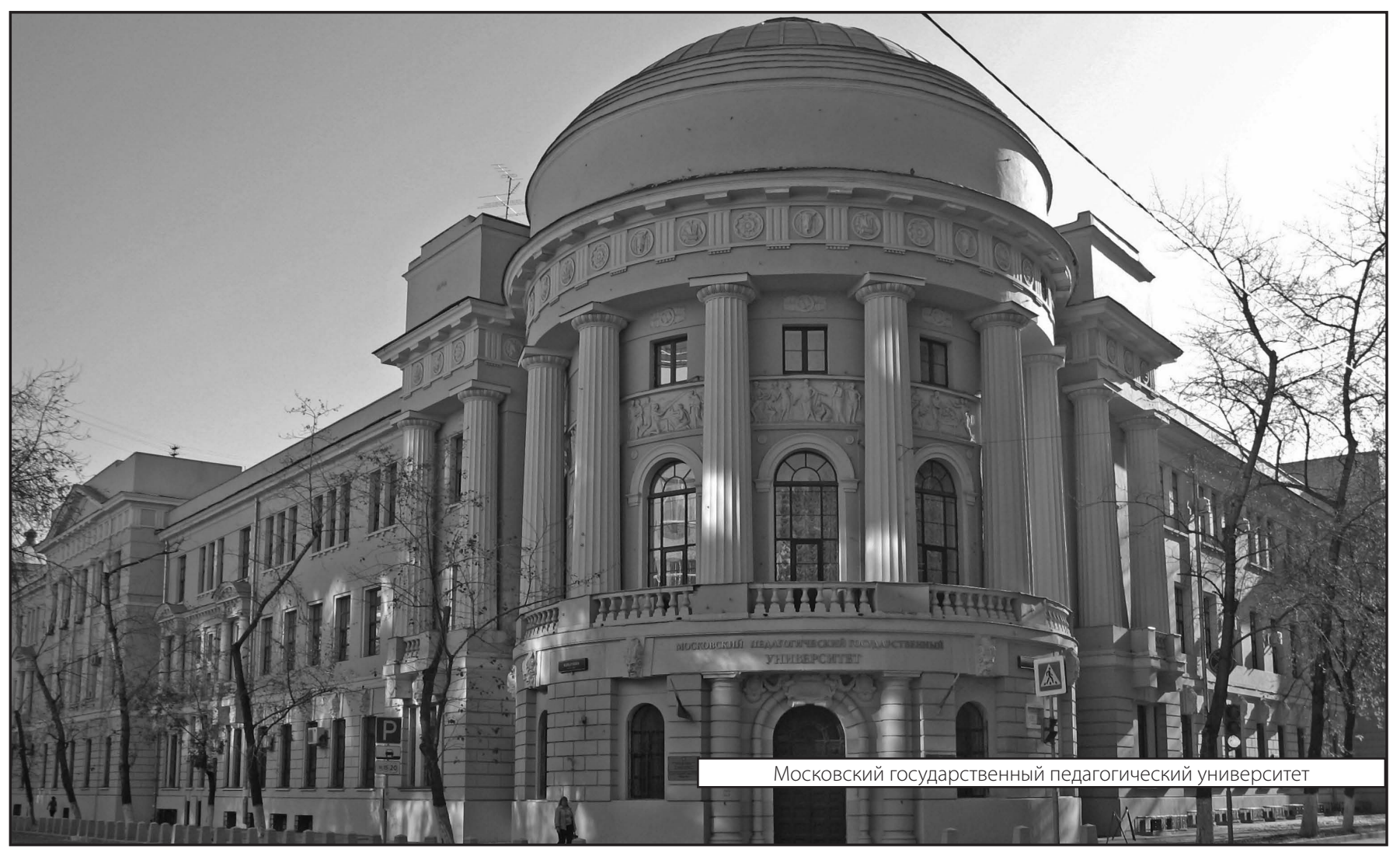

